Personal, Relational, and Contextual Resources and Relationship Satisfaction in Same-Sex Couples

By: Amber L. Pope, Christine E. Murray, A. Keith Mobley

Pope, A. L., Murray, C. E., \& Mobley, A. K. (2010). Personal, relational, and contextual resources and relationship satisfaction in same-sex couples. The Family Journal, 18(2), 163-168.

Made available courtesy of Sage Publications : http://dx.doi.org/10.1177/1066480710364501

***(C) Sage Publications. Reprinted with permission. No further reproduction is authorized without written permission from Sage Publications. This version of the document is not the version of record. Figures and/or pictures may be missing from this format of the document. $* * *$

Abstract:

Despite previous research findings that suggest that same-sex couples often experience unique stressors within their relationships, other findings indicate that same-sex couples demonstrate similar levels of relationship satisfaction as compared with heterosexual couples. The study described in this article was conducted to examine the extent to which various personal, relationship, and contextual resources may contribute to relationship satisfaction among individuals in same-sex couples. The findings indicated that individuals in same-sex couples may have more variability in the levels of support they receive from contextual resources. In addition, relationship resources were predictive of relationship satisfaction among the study participants, although personal and contextual resources did not contribute any unique variance to relationship satisfaction. The article concludes with implications for theory, practice, and research in couple and family counseling.

Keywords: same-sex couples | relationship satisfaction | couple and family counseling Article:

Scholars have hypothesized that same-sex couples may experience diminished relationship functioning and lower levels of relationship satisfaction as compared to heterosexual couples in light of the unique challenges they face as lesbian, gay, and bisexual (LGB) individuals (Otis, Rostosky, Riggle, \& Hamrin, 2006; Peplau \& Fingerhut, 2007). First, despite the increased visibility and acceptance of LGB individuals in the United States, homonegative attitudes (i.e., stances that denigrate LGB identities) still pervade many segments of society (Green \& Mitchell, 2002; Kurdek, 2004). In addition, because same-sex marriages remain illegal in most states (National Conference of State Legislatures, 2008), these couples lack the legal protections, privileges, and formal recognition ceremonies available to heterosexual couples who are permitted to marry. Moreover, same-sex couples consistently perceive less general social support and perceived support for their relationship than heterosexual dyads (Julien, Chartrand, \& Bégin, 
1999; Kurdek, 2004, 2006), and thus the lack of perceived social support and dissatisfaction with social support from families-of-origin and friends is associated with lower relationship satisfaction (Kurdek, 1988, 2004; Rostosky et al., 2004). Therefore, same-sex couples may experience added stressors on their relationships as a result of being a stigmatized minority (Rostosky, Riggle, Gray, \& Hatton, 2007).

Despite these unique challenges, researchers have demonstrated that same-sex couples function similarly to and report comparable levels of relationship satisfaction to heterosexual couples (Kurdek, 2004, 2006; Peplau \& Fingerhut, 2007). These findings suggest that same-sex couples may develop and use unique resources and strengths that help them to navigate the relationship challenges they face. The current literature is limited, however, by a lack of research identifying or addressing the unique resources that contribute to positive relationship outcomes among samesex couples. The aim of the current study was to explore the extent to which personal, relational, and contextual resources contribute to positive relationship satisfaction among individuals involved in same-sex couples.

\section{Review of the Literature}

\section{A Strengths-Based Theoretical Framework: Solution-Focused Couples Therapy}

The current study is grounded in Solution-Focused Therapy (SFT), which was developed by Steve de Shazer and colleagues (O’Connell, 1998). SFT is a strengths-based approach to counseling (Murray, 2007). Using clients' existing resources and assisting them in developing new resources that they can use while they work toward change is the basis of SFT, which assumes that clients have the capacity to create their own solutions (Murray, 2007). SFT has been applied to counseling with couples (e.g., Friedman \& Lipchik, 1999; Murray \& Murray, 2004). However, we were unable to locate through searches of the scholarly database, PsycINFO, any articles that present a specific application of this theory to working with samesex couples.

Based on SFT, Murray and Murray (2004) proposed a three-level framework for understanding the types of resources that support couples in their relationships. This framework, called the Couple's Resource Map, was devised originally as a qualitative assessment and intervention strategy in which couples are asked to describe the level of support they receive from various personal, relationship, and contextual resources. Personal resources are defined as those that are internal and unique to the individual (e.g., self-esteem and coping skills); relationship resources are resources that are shared between partners in an intimate relationship (e.g., relationship skills and knowledge about one's partner); and contextual resources encompass resources that exist within the larger social context surrounding the couple (e.g., family members and friends) (Murray \& Murray, 2004). Using this framework, Murray (2007; Murray \& Forti, 2009) developed a three-subscale instrument, the Couples Resource Map Scales (CRMS), as a means for empirically assessing the resources within the Couple’s Resource Map. Among a sample of 
1,103 participants that included mostly individuals in heterosexual relationships (94.2\%), Murray and Forti (2009) found that participants' relationship resource scale and personal resource scale scores were statistically significant predictors of their levels of relationship satisfaction. Therefore, theoretical and empirical support exists for the notion that resources promote relationship satisfaction, although the extent to which this is true for same-sex couples has not yet been determined.

\section{Functioning and Relationship Satisfaction in Same-Sex Couples}

A growing body of research shows that same-sex couples function similar to, and in some areas possibly more effectively than, heterosexual couples, and that same-sex couples report levels of relationship satisfaction comparable to heterosexual couples (Kurdek, 2004, 2006; Peplau \& Fingerhut, 2007). Thus, same-sex partners appear to bring strengths and resources to their relationships despite challenges they face as a stigmatized minority. This may be especially true in certain relationship domains, such as negotiating a fair balance when dividing household labors because they are unable to rely on assigning tasks based on gender norms, and thus may be more flexible and creative than heterosexual couples in dividing labors (Kurdek, 2006; Peplau \& Fingerhut, 2007). Moreover, same-sex partners have reported giving more individual effort to resolve conflict, perceiving more effort on behalf of their partner, being more constructively assertive rather than aggressive during times of conflict, and presenting issues of conflict in a more positive manner than heterosexual couples (Gottman, Levenson, Swanson, et al., 2003; Kurdek, 2004; Metz, Rosser, \& Strapko, 1994).

Thus, a growing body of research demonstrates positive relational functioning among same-sex couples, including areas in which they may function better than their heterosexual counterparts; however, the existing literature primarily includes studies that assess same-sex couples from a deficit framework (i.e., are same-sex couples different from, or possibly inferior to as the stereotype suggests, heterosexual couples?) as researchers had to begin at discrediting the societal stereotype that same-sex couples' relationships are dysfunctional or substandard to heterosexual relationships (Kurdek, 2004; Peplau \& Fingerhut, 2007). Moreover, many researchers tend to look at how homonegative attitudes and minority stress affects same-sex couples and the resulting challenges they face (e.g., Balsam \& Szymanski, 2005; Otis et al., 2006; Rostosky et al., 2007), rather than looking at the resources same-sex partners already possess, which can be used in their relationships to create positive relationship functioning. Thus, the current study explores same-sex couples' relationships from a strengths based framework to investigate the resources that are related to positive relationship satisfaction.

\section{Methodology}

\section{Sample and Recruitment Strategies}

We aimed to recruit a sample of participants involved in same-sex intimate relationships for this study. We used a variety of sample recruitment strategies to achieve a convenience sample 
encompassing those backgrounds. First, we sent e-mails to listserves and contacts within organizations that serve the LGB community locally and nationally. Second, we created fliers describing the study, which were handed out to individuals attending a local LGB Pride festival. Third, we posted announcements about the study on electronic bulletin boards for groups relevant to the LGB community on Facebook and MySpace, as well as on Internet message and discussion boards on relevant Web sites. Snowball sampling was incorporated, in that we asked participants who received the invitation to participate via e-mail to forward the survey to any contacts who they believed might be interested in this study. The eligibility criteria for this study were being over the age of 18 and being currently involved in a committed intimate relationship with a person of the same sex. For the purposes of this study, a committed intimate relationship was defined as a relationship in which two individuals share an emotional, romantic, and/or sexual connection, and both intend to share a long-term relationship with one another.

Participants were recruited at the individual level and, because the survey was anonymous, it was not possible to determine whether partners in the same relationship both participated in this study.

\section{Instrumentation}

In addition to a demographic questionnaire assessing characteristics of participants and their relationships, the instrumentation used in this study included the Personal, Relationship, and Contextual Resource Area Subscales of the CRMS (Murray, 2007; Murray \& Forti, 2009) and the Relationship Assessment Scale (RAS; Hendrick, 1988).

The CRMS. The CRMS is a 63-item instrument designed to measure the amount of support an individual receives for his or her intimate relationship from various personal, relationship, and contextual resources (Murray, 2007; Murray \& Forti, 2009). This study focused on the three main CRMS subscales: the Personal Resource Area Scale (PRAS), the Relationship Resource Area Scale (RRAS), and the Contextual Resource Area Scale (CRAS). Two previous studies (Murray, 2007; Murray \& Forti, 2009) examined the psychometric properties of the CRMS. In both of these previous studies, the majority of participants were involved in heterosexual relationships. In Murray (2007), only 11 (2.8\%) of the 397 total participants were involved in same-sex relationships, whereas in Murray and Forti, participants involved in same-sex relationships represented only 63 (5.7\%) of the 1,040 total participants. Therefore, the current study represents the first use of the CRMS with an exclusively same-sex relationship involved sample. The CRMS total scale and subscales have demonstrated strong internal consistency in the previous studies. The Cronbach's a coefficients for the CRMS scales in Murray (2007) were as follows: CRMS total scale $(\mathrm{a}=.94)$, PRAS $(\mathrm{a}=.88)$, RRAS $(\mathrm{a}=.92)$, and CRAS $(\mathrm{a}=.86)$. Murray and Forti (2009) found the following Cronbach's a coefficients for the various scales: CRMS total scale $(\mathrm{a}=0.93)$, PRAS $(\mathrm{a}=0.85)$, RRAS $(\mathrm{a}=0.90)$, and CRAS $(\mathrm{a}-0.84)$. The validity of the CRMS Personal, Relationship, and Contextual Resource Area Scales has been supported by demonstrating their relationships in the expected directions with self-esteem, relationship satisfaction, and social support, respectively (Murray \& Forti, 2009). 
The RAS. The RAS (Hendrick, 1988) is a brief (7 items) instrument that measures respondents' general level of satisfaction with their intimate couple relationship (Corcoran \& Fischer, 2000). The RAS was chosen for this study because its items are gender neutral, with such questions as "How well does your partner meet your needs?" and "'To what extent has your relationship met your original expectations?” The RAS demonstrates good internal consistency, with a Cronbach's $\alpha$ of .86, and its concurrent and predictive validity have been established (Corcoran $\&$ Fischer, 2000). Although no psychometric data on the use of RAS with same-sex couples could be found through searching scholarly databases (PsycINFO and LGBT Life), the instrument has been used to assess relationship satisfaction among same-sex couples in two doctoral dissertation studies (Finch, 1999; Tolentino, 2006).

\section{Data Collection Procedures}

The study was approved by the university's Institutional Review Board. Data collection occurred entirely online for this study. A separate section of the CRMS Web site was set up to host this project specific to same-sex relationships. Through the various recruiting methods, participants were directed to the survey Web site address. Participants read and were required to indicate their agreement to the informed consent procedures before they could access the instrumentation. All survey responses were anonymous. After participants submitted their surveys, they received the printable feedback in the form of the Couple's Resource Map depicting the amount of support they receive for their relationship from the various resources included on the map. As an additional incentive for participation, participants were offered the opportunity to enter into a drawing for one of three $\$ 50$ store gift cards. The data collection period lasted from April to November 2008.

\section{Results}

\section{Description of the Sample}

Ninety-five participants completed the entire survey. The participants ranged in age from 18 to 68 , with a mean of 37.2 years $(S D=11.23)$. Participants reported that their partners also ranged in age from 18 to 68 , with a mean of 38.1 years ( $\mathrm{SD}=11.44)$. The length of participants' relationships with their current partners ranged from approximately 4 months to 36 years. The average relationship length was 7.1 years ( $\mathrm{SD}=7.1$ ). Additional demographic characteristics of the sample can be found in Table 1. Seventy-nine (83.2\%) participants reported that they share a household with their partners, and among these participants, the average length of living together was 7.4 years $(S D=7.6)$. Ninety participants $(94.7 \%)$ reported that their relationships with their partners are monogamous. The participants represented geographic diversity; 28 states and the District of Columbia were represented in the sample, plus one participant from Australia.

There were no significant correlations between participants' ages or relationship lengths and their scores on the study instrumentation. In addition, one-way analyses of variance (ANOVAs) were used to test whether participants differed in their scores on the study instrumentation (i.e., 
the PRAS, RRAS, CRAS, and RAS) based on certain background characteristics. There were no significant differences found on any of the instrumentation based on gender, whether the relationships were monogamous, and counseling participation. However, there were differences in participants reported relationship satisfaction ( $\mathrm{df}=1, \mathrm{~F}=6.04, \mathrm{p}=.02$ ), personal resources ( $\mathrm{df}$ $=1, \mathrm{~F}=4.17, \mathrm{p}=.04)$, and relationship resources $(\mathrm{df}=1, \mathrm{~F}=7.3, \mathrm{p}=.01)$ based on whether participants shared a household with their partners. For all three of these variables, participants who lived with their partners (RAS: $M=29.9$; $S D=4.81$; PRAS: $M=58.7$; $S D=6.04$; RRAS: $\mathrm{M}=59.1$; $\mathrm{SD}=8.13$ ) had higher scores as compared to participants who did not live with their partners (RAS: $\mathrm{M}=$ 26.6; $\mathrm{SD}=5.41$; PRAS: $\mathrm{M}=$ 55.4; $\mathrm{SD}=4.7$; RRAS: $\mathrm{M}=53.2$; $\mathrm{SD}=7.33$ ). However, due to such a small proportion $(n=16 ; 16.8 \%)$ of the sample representing couples who did not live together, we were unable to control for this difference in subsequent analyses. Therefore, this remains an important area for further investigation in future studies.

Table 1. Demographic Characteristics of the Sample

\begin{tabular}{|c|c|c|}
\hline Characteristic & Frequency & Percentage \\
\hline \multicolumn{3}{|l|}{ Gender } \\
\hline Male with male partner & 41 & 43.2 \\
\hline Female with female partner & 54 & 56.8 \\
\hline \multicolumn{3}{|l|}{ Ethnic background } \\
\hline Caucasian & 88 & 92.6 \\
\hline Hispanic & 3 & 3.2 \\
\hline Multiethnic & 2 & 2.1 \\
\hline African American & 1 & 1.1 \\
\hline Asian American & 1 & 1.1 \\
\hline \multicolumn{3}{|l|}{ Partner's ethnic background } \\
\hline Caucasian & 83 & 87.4 \\
\hline Multiethnic & 5 & 5.3 \\
\hline African American & 3 & 3.2 \\
\hline Hispanic & 3 & 3.2 \\
\hline \multicolumn{3}{|c|}{ Highest education level completed } \\
\hline No high school diploma & 1 & 1.1 \\
\hline GED/high school diploma & 21 & 22.1 \\
\hline Some college, no degree & 9 & 9.5 \\
\hline Associate’s degree & 16 & 16.8 \\
\hline Bachelors degree & 38 & 40.0 \\
\hline Graduate degree & 10 & 10.6 \\
\hline \multicolumn{3}{|l|}{ Annual income of participant } \\
\hline$\leq \$ 15,000$ & 19 & 20.0 \\
\hline$\$ 16,000$ to $\$ 15,000$ & 10 & 10.5 \\
\hline$\$ 26,000$ to $\$ 35,000$ & 17 & 17.9 \\
\hline$\$ 36,000$ to $\$ 45,000$ & 12 & 12.6 \\
\hline$>\$ 45,000$ & 37 & 38.9 \\
\hline
\end{tabular}




\begin{tabular}{|l|l|l|}
\hline Currently in couples counseling & 5 & 5.3 \\
\hline Ever in couples counseling & 14 & 14.7 \\
\hline Currently in individual counseling & 22 & 23.2 \\
\hline Number of children \\
\hline Children together with partner \\
\hline 0 & 87 & 91.6 \\
\hline One or more & 8 & 8.5 \\
\hline Children from participants' previous relationships \\
\hline 0 & 77 & 81.1 \\
\hline One or more & 18 & 19.0 \\
\hline Children from participants' partners' previous relationships \\
\hline 0 & 82 & 86.3 \\
\hline One or more & 13 & 13.7 \\
\hline
\end{tabular}

Note: The percentages reported in this table represent percentage of the total sample. GED = General Education Diploma.

Internal Consistency of the Instrumentation

Cronbach's a coefficients for the scales used in this study were computed to examine their internal consistency for use with individuals in same-sex couples. The coefficients for each scale are as follows: CRMS total scale $(\mathrm{a}=.91)$, PRAS $(\mathrm{a}=.84)$, RRAS $(\mathrm{a}=.91)$, CRAS $(\mathrm{a}=.71)$, and RAS $(\mathrm{a}=.90)$.

\section{Prediction of Relationship Satisfaction Based on Resource Area}

The range, mean, and standard deviations of participants' scores on the instruments used for this study are presented in Table 2. Table 3 presents a correlation matrix of the study instruments. As indicated, there were significant, positive correlations between all of the variables. To determine which of the resource areas could be used to predict relationship satisfaction, we conducted a regression analysis with PRAS, RRAS, and CRAS scores as the independent variables and RAS scores as the dependent variable. The overall model was shown to be statistically significant ( $\mathrm{F}=$ $56.002, \mathrm{df}=3, \mathrm{p}=.000$ ) and explained $64 \%$ of the variance in participants' RAS scores. However, only the RRAS scale $(\mathrm{b}=.752, \mathrm{t}=8.489, \mathrm{p}=.000)$ was a significant predictor variable; PRAS $(\mathrm{b}=.080, \mathrm{t}=0.872, \mathrm{p}=.386)$ and CRAS scale scores $\left(\mathrm{b}=\ldots .008, \mathrm{t}=\_0.120, \mathrm{p}=\right.$ .904) did not account for any unique variance in addition to the variance accounted for by the RRAS. Therefore, although all three resource area scales demonstrated significant positive correlations with relationship satisfaction, only the relationship resource area was a significant predictor of relationship satisfaction.

\section{Discussion}

The findings of the current study provide a strengths-based conceptualization of the resources that same-sex couples bring to their relationships and how these relate to their relationship satisfaction. First, the results of this study further support that same-sex couples function 
similarly to heterosexual couples. The internal consistency ratings for the CRMS total scale and the PRAS and RRAS scales were consistent with the ratings found in previous studies, which suggests that same-sex couples responded similarly to heterosexual couples who took the instrument. The CRAS scale, however, had a more marginal internal consistency rating in this study as compared to previous studies with heterosexual couples. This suggests that same-sex couples may demonstrate greater variability in the levels of support they receive from each of the specific contextual resources assessed. These findings are consistent with previous studies that have shown same-sex couples perceive less support from their families of origin (Julien et al., 1999; Kurdek, 2004, 2006; Rostosky et al., 2004) and therefore may compensate by creating a social support network of LGB-affirming friends, social groups, or organizations (Green \& Mitchell, 2002; Julien et al., 1999; Kurdek, 1988; Peplau \& Fingerhut, 2007). Therefore, the role of contextual resources in same-sex couples’ relationships warrants further investigation.

Another finding of note is that only relationship resources contributed uniquely to relationship satisfaction of same-sex couples, whereas relationship resources and personal resources significantly contributed to relationship satisfaction in the two previous studies of the instrument, using predominantly heterosexual samples. At the present time, we can only speculate as to the reasons for this finding. Perhaps same-sex couples have a more salient need to develop relationship resources due to the stigma and discrimination that they encounter from society as a same-sex couple. Moreover, previous studies have suggested that minority stressors, particularly internalized homonegativity (i.e., attitudes that denigrate LGB identities), may affect the psychological adjustment of LGB individuals and consequently the relationship satisfaction of same-sex partners (Balsam \& Szymanski, 2005; Otis et al., 2006; Rostosky et al., 2007). Internalized homonegativity may have influenced how same-sex partners responded to the personal resources area, and thus may have affected the relationship between personal resources and relationship satisfaction in this study. The relationship between internalized homonegativity and personal resources is an area to be explored in future research. Additionally, as suggested by previous research (e.g., Gottman et al., 2003; Kurdek, 2004, 2006; Metz et al., 1994; Peplau \& Fingerhut, 2007), same-sex relationship functioning may be particularly strong in some areas (e.g., the division of labor, communication skills, and conflict management) as a result of the opportunities they have to define their relationships without strong gender role norms. Therefore, other types of resources may be overshadowed by such strong relationship resources. Finally, it is important to note the strong correlation between personal and relationship resources among the sample, which suggests that, personal resources may be so overlapping with relationship resources that personal resources may serve as a foundation for healthy same-sex relationship functioning.

Table 2. Ranges, Means, and Standard Deviations for Study Instrumentation

\begin{tabular}{|l|l|l|l|l|l|l|}
\hline Measure & $\begin{array}{l}\text { Possible } \\
\text { Minimum }\end{array}$ & $\begin{array}{l}\text { Possible } \\
\text { Maximum }\end{array}$ & $\begin{array}{l}\text { Actual } \\
\text { Minimum }\end{array}$ & $\begin{array}{l}\text { Actual } \\
\text { Maximum }\end{array}$ & M & SD \\
\hline PRAS & 18 & 72 & 45 & 72 & 58.2 & 5.9 \\
\hline
\end{tabular}




\begin{tabular}{|l|l|l|l|l|l|l|}
\hline RRAS & 18 & 72 & 37 & 72 & 58.1 & 8.3 \\
\hline CRAS & 27 & 108 & 58 & 93 & 74.7 & 7.4 \\
\hline RAS & 7 & 35 & 15 & 35 & 29.4 & 5.0 \\
\hline
\end{tabular}

Note: CRAS = Contextual Resource Area Scale; PRAS = Personal Resource Area Scale; RAS = Relationship Assessment Scale; RRAS = Relationship Resource Area Scale.

Table 3. Correlation Matrix for Study Instrumentation

\begin{tabular}{|l|l|l|l|}
\hline & PRAS & RRAS & CRAS \\
\hline PRAS & - & & \\
\hline p value & & & \\
\hline RRAS & 0.71 & - & \\
\hline p value & .000 & & \\
\hline CRAS & 0.48 & 0.40 & - \\
\hline p value & .000 & .000 & \\
\hline RAS & 0.61 & 0.81 & 0.32 \\
\hline p value & .000 & .000 & .002 \\
\hline
\end{tabular}

Note: CRAS = Contextual Resource Area Scale; PRAS = Personal Resource Area Scale; RAS = Relationship Assessment Scale; RRAS = Relationship Resource Area Scale.

Finally, this study found that same-sex partners who shared the same household reported significantly higher relationship satisfaction and more personal and relationship resources than the participants who did not. This finding is logical, in that those couples who have higher relationship satisfaction and more resources would be more likely to take steps toward making their relationships more committed (i.e., living together) than couples who are less satisfied in their relationships. The portion of our sample who did not live together, however, was so small that this finding should be considered with caution and thus needs to be investigated further.

\section{Limitations}

This research study demonstrates several limitations. First, this study was conducted using a convenience sample that limits the generalizability of our findings. Due to the manner in which participants were recruited, they were more likely to be affiliated with LGB organizations and to have an identity as a member of the LGB community. The participants were also mostly Caucasian. Another limitation is that we allowed participants to define "committed intimate relationship" rather than defining it for them based on the length of time together. Therefore, the relationship length of our participants varied from 4 months to 36 years. Although we found no correlations between relationship length and scores on our measurements, this variation in relationship length may have affected our results in ways we cannot detect or interpret with a small sample. Similarly, other characteristics such as age, gender, monogamy, and counseling participation did not affect variations in responses; differences which may have been imperceptible due to our small sample size. Finally, because of the anonymous response format, we were unable to determine whether any participants were in a relationship with each other. 
Thus, if both partners in the same couple participated in this study, dynamics involved in that relationship could be overrepresented in the findings.

\section{Implications for Practice, Theory, and Research}

The CRMS provides the counseling profession with a strengths based means of assessing, conceptualizing, and explaining the personal, relationship, and contextual resources that samesex partners bring to their relationships. From a SFT perspective, clinicians should draw on the strengths and resources of the individual partners and the couple to help move them toward meeting their stated therapeutic goals (Murray, 2007). The CRMS can be used by couple and family counselors to explore the unique resources and strengths of same-sex couples who present to counseling. Based on the finding that relationship resources were predictive of relationship satisfaction, clinicians can use primary interventions to enhance relationship resources. Clinicians can also support their clients in mobilizing the relationship resources of same-sex couples to help the couple manage minority stress (i.e., enhance contextual resources).

This study adds to theoretical conceptualization of same-sex couples by exploring their relationship functioning from a strengths-based perspective. Findings related to the role of various personal, relationship, and contextual resources within same-sex relationships add to the counseling profession's understanding of these couples. There is a need to look further at these resources, as our study suggests that same-sex couples may perceive their resources, particularly at the contextual level, differently than heterosexual couples from previous studies.

Finally, the findings of this study suggest multiple directions for future investigation of the relationship functioning and satisfaction of same-sex couples. First, a larger sample would allow researchers to look more specifically at perceived resources of same-sex partners, particularly in the contextual area, to provide further clarification of the strengths same-sex partners typically bring to their relationships and the areas in which same-sex couples may need to develop more support. The impact of cohabitation on relationship satisfaction and personal and relationship resources also can be investigated further in studies with larger sample sizes. Furthermore, as previous studies have found internalized homonegativity to influence relationship satisfaction in same-sex partners (Balsam \& Szymanski, 2005; Otis et al., 2006), the impact of internalized homonegativity on the perceived resources of same-sex relationships should be explored. Finally, future research can examine dyadic data to identify similarities in same-sex partners' reporting of resources.

This study examined the resources of same-sex partners and the impact of those resources on their relationship satisfaction. Using the CRMS with same-sex couples offers the counseling profession a strengths-based approach to exploring and assessing same-sex partners' resources, strengths, and assets rather than focusing solely on the challenges and deficits they may face in comparison to heterosexual couples. Although these challenges do influence the relationship functioning and satisfaction of same-sex couples, the findings of this study suggest that same-sex 
partners already possess multiple resources that they can draw upon to create satisfying relationships and navigate the stressors that arise from being a stigmatized minority.

\section{Declaration of Conflicting Interests}

The authors declared no potential conflicts of interests with respect to the authorship and/or publication of this article.

\section{Funding}

The authors disclosed receipt of the following financial support for the research and/or authorship of this article: This study was supported by a research grant from the Guilford Green Foundation in Greensboro, North Carolina.

\section{References}

Balsam, K., \& Szymanski, D. (2005). Relationship quality and domestic violence in women's same-sex relationships: The role of minority stress. Psychology of Women Quarterly, 29, 258269.

Corcoran, K., \& Fischer, J. (2000). Measures for clinical practice: A Sourcebook: Volume 1: Couples, families, and children (3rd ed.). New York: The Free Press.

Finch, T. M. (1999). Relationship satisfaction among lesbian couples: The effects of fusion and love styles. Dissertation Abstracts International: Section B: The Sciences and Engineering, 60 (6B), 3016.

Friedman, S., \& Lipchik, E. (1999). A time-effective, solution-focused approach to couple therapy. In J. M. Donovan (Ed.), Short-term couple therapy (pp. 325-359). New York: Guilford.

Gottman, J., Levenson, R., Swanson, C., Swanson, K., Tyson, R., \& Yoshimoto, D. (2003). Observing gay, lesbian, and heterosexual couples' relationships: Mathematical modeling of conflict interaction. Journal of Homosexuality, 45, 65-91.

Green, R. J., \& Mitchell, V. (2002). Gay and lesbian couples in therapy: Homophobia, relational ambiguity, and social support. In A. S. Gurman \& N. S. Jacobson (Eds.), Clinical handbook of couple therapy (3rd ed., pp. 546-568). New York: Guilford.

Hendrick, S. S. (1988). A generic measure of relationship satisfaction. Journal of Marriage and the Family, 50, 93-98.

Julien, D., Chartrand, E., \& Be'gin, J. (1999). Social networks, structural interdependence, and conjugal adjustment in heterosexual, gay, and lesbian couples. Journal of Marriage and the Family, 61, 516-530. 
Kurdek, L. A. (1988). Perceived social support in gays and lesbians in cohabitating relationships. Journal of Personality and Social Psychology, 54, 504-509.

Kurdek, L. A. (2004). Are gay and lesbian cohabiting couples really different from heterosexual married couples? Journal of Marriage and Family, 66, 880-900.

Kurdek, L. A. (2006). Differences between partners from heterosexual, gay, and lesbian cohabiting couples. Journal of Marriage and Family, 68, 509-528.

Metz, M., Rosser, B. R., \& Strapko, N. (1994). Differences in conflict resolution styles among heterosexual, gay, and lesbian couples. The Journal of Sex Research, 31, 293-308.

Murray, C. E. (2007). Development of the Couples Resource Map Scales. Journal of Couple \& Relationship Therapy, 6, 49-70.

Murray, C. E., \& Forti, A. M. (2009). Validation of the Couples Resource Map Scales. Journal of Couple and Relationship Therapy, 8, 209-225.

Murray, C. E., \& Murray, T. L. (2004). Solution-focused premarital counseling: Helping couples build a vision for their marriage. Journal of Marital and Family Therapy, 30, 349-358.

National Conference of State Legislatures. (2008). Same-sex marriage, civil unions and domestic partnerships. Retrieved February 18, 2009, from http://www.ncsl.org/programs/cyf/samesex.htm

O’Connell, B. (1998). Solution-focused therapy. London: SAGE.

Otis, M., Rostosky, S., Riggle, E., \& Hamrin, R. (2006). Stress and relationship quality in samesex couples. Journal of Social \& Personal Relationships, 23, 81-99.

Peplau, L. A., \& Fingerhut, A. W. (2007). The close relationships of lesbians and gay men. Annual Review of Psychology, 58, 405-424.

Rostosky, S., Korfhage, B., Duhigg, J., Stern, A., Bennett, L., \& Riggle, E. (2004). Same-sex couple perceptions of family support: A consensual qualitative study. Family Process, 43, 43-57.

Rostosky, S., Riggle, E., Gray, B., \& Hatton, R. (2007). Minority stress experiences in committed same-sex couple relationships. Professional Psychology: Research and Practice, 38, 392-400.

Tolentino, A. C. (2006). An investigation of counseling effectiveness on enhancing relationship satisfaction: Focus on heterosexual, lesbian, gay, and bisexual couples. Dissertation Abstracts International: Section B: The Sciences and Engineering, 67 (4-B), 2248. 